\title{
Covid-19, Socialization, and Social Change in Calabar Metropolis of Cross River State, Nigeria
}

\author{
Edinyang Sunday David, Ogbaji Ipuole Dominic, Iwara Helen Benedict
}

\begin{abstract}
The impact of covid-19 on different facets of life cannot be overemphasized, especially on socialization. Socialization is a way of life of the people, especially in the way they relate with one another and their engagement in social activities. The purpose of this study was to investigate the influence of Covid-19 on the socialization of the people of Calabar Metropolis in Cross River State, Nigeria. A simple survey design was used for the study. A total of 200 respondents were systematically sampled from the study area. Mainly, data were collected from respondents in their residents using a questionnaire designed by the researcher to determine the effect of Covid-19 on the socialization of the metropolitans. The survey had ten items that were used to elicit responses, of which some were open-ended while some were close-ended questions. Data were collected within 18 days. Data collected were sorted, coded, credited, and analyzed using Statistical Package for Social Sciences (SPSS) version 20 software. The hypothesis set was tested using simple regression analysis significant at a $95 \%$ Confidence Interval $(\mathbf{0 . 0 5})$. The results were presented using descriptive and inferential statistics. The following were the identified effects of Covid-19 on socialization: people relationship $135(67.5 \%)$, affecting religious worship life $167(83.5 \%)$, buying pattern $110(55.0 \%)$, people's exercise and physical activity $134(67.0 \%)$, outing patterns $200(100 \%)$, health consciousness 89(44.5\%), and personal hygiene 98(49.0\%). People avoided handshakes 140(70.0\%), embrace 102(51.0\%), and hospitals for fear of being diagnosed of Covid-19 of contacting it from health workers or patients $65(32.5 \%)$ while increased frequent hand washing $\mathbf{7 0}(35.0 \%)$, the use of face mask $180(90.0 \%)$ and use of hand sanitizers $83(41.5 \%)$. The hypothesis stated showed that there is a significant influence of covid-19 on socialization $(P<.000)$. Continuous adherence to precautionary social measures was recommended, among others.
\end{abstract}

Index Terms - Covid-19, Socialization, Social change, Social activities.

\section{INTRODUCTION}

The effect of covid-19 on various aspects of life, in particular on socialization, can not be overemphasized. The 2019 (Covid-19) pandemic of the coronavirus (SARS-CoV-2) disease is a severe psychosocial and global health emergency. Corona 2019 virus affects every part of the lives of peoples and accelerates social transformations. The pandemic 's global scope enables scientists to compare backgrounds and

Edinyang Sunday David, Associate Professor in the Department of Social Science Education, Faculty of Education, University of Calabar, Calabar, Cross River State, Nigeria

Ogbaji Ipuole Dominic, Lecturer in the Department of Social Science Education, Faculty of Education, University of Calabar, Calabar, Cross River State

Iwara Helen Benedict, Masters Degree Student with the Department of Social Science Education, Faculty of Education, University of Calabar, Cross River State, Nigeria. societies, while unparalleled media reporting of this psychosocial phenomenon facilitates a study of cultural viewpoints. The Covid-19 pandemic 's impact differs between socioeconomic strata, age cohorts, class, culture, and personality, particularly the socialization of humans that had a new dimension that brought about social change (Jeronimus, 2020). The Covid-19 pandemic is a large-scale disruptive and traumatic catastrophe event because it causes widespread disruption, suffering, and loss of life to a significant number of people across one or more social strata (such as older people and those with chronic diseases) and needs considerable individual and social readjustment. According to Jeronimus (2020), who believed that disasters like Covid-19 are represented just as much as social events are physical, disturbing the everyday lives of man, and how they behave in their social roles, and how people organize their social networks.

Socialization is people's way of life, particularly in the way they relate to each other and the way they participate in social activities. Socialization usually refers to the process of social control by which an person acquires its community or locality / environment culture or subculture. The self and personality of the individual are developed during the learning of these cultural elements. It lets people become professional in their societies. Socialization is a sociological process that takes place through socialization. It is a cycle by which culture is recreated, but the Covid-19 epidemic did not allow this cycle to proceed, but rather led to social change. At the other hand, social change entails changing a society's social structure, and it requires changes in social structures, social attitudes, and social ties. In addition to the impact of Covid-19 on people's socialisation, the World Health Organisation (WHO) has pointed out that the Covid-19 pandemic has impacted people's mental wellbeing (WHO, 2020). This impact on mental health of individuals has resulted in people's social adjustment to the way they relate to each other and how they react to society.

However, the World Health Organization ( WHO ) declared in January 2020 the spread of a new coronavirus disease, COVID-19, to be an emergency of public health concern worldwide. This is because they, like all social activities, are shaped as parts of the world. WHO has stated that COVID-19 is very likely to spread to other countries across the world. In March 2020, the WHO classified COVID-19 as being known as a pandemic. The World Health Organization and public health authorities around the world are working to contain COVID-19 outbreak, but this time of crisis is causing uncertainty across the population. Together with the Covid-19 outbreak which instigated the study, it focused on 
these observed social background problems.

\section{STATEMENT OF PROBLEM}

It is no doubt that the spread of Covid-19 globally down to rural communities has been a thing of worry to all. This case has been worrisome as it affected the way people relate with one another. Mainly, the people in Calabar Metropolis are used to handshakes and embrace in exchanging pleasantries, gathering together in numbers to celebrate weddings, birthdays, and peoples' successes as well as collect in religious worship centers, market places, clubs, schools, and town halls. However, the researchers observed that the outbreak of Covid-19 has brought about a downturn in the usual way the people were used to living their lives. The researchers also noted that the hitch in this former way of socialization had been a thing of worry to the people as many could not go out freely to make ends meet, relate with others, and get their goals and dreams fulfilled. No matter how this may look in the containment of the pandemic, the researchers perceive a social problem related to the pandemic, and it is because of this perceived problem the researchers were interested in investigating the influence of Covid-19 on the socialization of the people.

\section{PURPOSE OF THE STUDY}

The purpose of this study was to investigate the influence of Covid-19 on the socialization of the people of Calabar Metropolis in Cross River State, Nigeria.

\section{LITERATURE REVIEW}

The Covid-19 pandemic isn't news anymore around the world. The 2019 novel coronavirus (2019-nCoV) has changed the way we act, interact and socialize. The first reported viral infection in Wuhan China has spread rapidly around the world, and the World Health Organization (WHO) has subsequently declared it a pandemic (Sun, He \& Wang, 2020; Wu, Wu \& Liu, 2020). Pathologically also known as COVID-19, the novel coronavirus primarily affects respiratory systems with devastating impacts in different body organs (Lai, Liu \& Wang, 2020). The virulence and pathogenicity of COVID-19 is severe in the elderly and is co-morbid in humans (Lupia, Scabini \& Pinna, 2020). With the first index case reported in Nigeria, Nigerian socialization has taken on a new dimension, as vaccines vital to preventing human infections are not yet available. As a result, individuals questioned how long the planet will stay in lockdown and when do we expect a return to normal times? Critical workers and other groups of people who would prefer to shop, use the taxi, visit the hospital and attend burials have been issued with instructions to prevent the pandemic, social or physical distance. Nigerians in general and the people of Calabar Metropolis in particular are used to embrace, and handshakes as a way of socializing, but social distancing has brought about a social change resulting from the Covid-19 outbreak. During these pandemics, social distancing steps have proven successful during minimizing the spread of disease (Jing, Lin \& Karen 2020).

Although social distance is anti-socialization, studies have shown that adherence to social distinctions can impede the spread of the pandemic. Experts added, however, that non-compliance with social distance guidelines in some countries causes a spike in infection rates as 80 percent of all infections result from non-compliance with social distance, especially during burial ceremonies (funerals), weddings / marriage ceremonies (Chen, Xu \& Lei, 2020). While the lockdown regulations permit up to 50 people to attend a funeral and other events, some families have disobeyed this regulation, leading to a surge of new cases of COVID-19 infection, especially in the Metropolitan region.

In general, social distancing is not practiced strictly at funerals, marriages, and other celebrations. Food and water are also shared, and people sit next to each other exchanging pleasantries, as this has been the pattern of socialization of the people of Africa, Nigeria, and Calabar Metropolis. However, Mouth covering with mask was not strictly adhered to. Another means for the transmission of virus-containing droplets is singing at funerals and churches / mosques. Throughout church services, congregants sing and pray loudly, sit next to each other and often touch surface / fomite that may be polluted (Jaja, Anyanwu \& Jaja 2020). Consequently this study will discuss the situation in Covid-19 Nigeria and how it affects socialization in Calabar Metropolis.

All these readjustments have a psychological origin in the social way of life. It first appears in the individual's mental health and brings to the individual's subconsciousness that if life is to be maintained, this pandemic needs better attention. Alvis, Douglas, Shook, and Oosterhoff (2020) conducted a study on the prosocial interactions of teenagers during the COVID-19 pandemic: mental health connections and group attachments. Using 437 respondents, a primary survey was used in the study where questionnaires were used for data collection and data analyzed using descriptive statistics. The study showed that respondents were re-adjusted due to the Covid-19 pandemic in socialization, and this change was first sub-conscious in the individuals ' mental wellbeing. The research, however, concluded that the pandemic had an effect on group socialization of the respondents.

\section{METHODOLOGY}

The research used a basic survey method. The field of research was Calabar Metropolis at Cross River State, Nigeria. Calabar, also known as Canaan City, is the capital city of Cross River State, situated in Nigeria 's geographical South-South region. This is parallel to the Calabar River and the Cross River Creeks and Great Kwa Rivers. The Metropolis is administratively divided into Calabar Municipal, and Calabar South Local Government Areas and is situated between Latitude 4048 North and Longitude 8017 East, respectively. It has an area of 406 square kilometers (i.e., it occupies an area of 210,936 square kilometers), and a projected population of 371,022 in 2016. National Population Commission (2015) reported that the Metropolis is estimated to have around 74,580 households, and there are also (11) wards in Calabar Municipality Local Government Area and thirteen (13) wards in Calabar South Local Government Area. In the North, Calabar Metropolis is bounded by local government areas of Odukpani and Akamkpa, in the East by 
the Great Kwa River, in the South the River Calabar bounds it. The research area consists of one federal university, one state university, one private university, one health technology college, and numerous secondary and elementary schools. The main dwellers are; the Efiks, the Efuts, and the Quas, whose widely spoken, common language is Efik and Ejagam. They use English as a communication medium, as well.

A total of 200 respondents from the study area were consistently sampled. In particular, data were gathered from respondents within their residents using a questionnaire developed by the researcher to assess the impact of Covid-19 on metropolitan socialization. The questionnaire had ten items, some of which were open-ended, and some were close-ended questions, which were used to get answers. The data were collected within 18 days. Using the Statistical Package for Social Sciences (SPSS) version 20 software, the data collected were sorted, coded, attributed, and analyzed. The collection of hypotheses was evaluated using a simple significant regression analysis at a confidence interval of 95 percent (0.05). The findings were described using statistics of a concise and inferential kind.

\section{RESULTS AND FINDINGS}

For the study, a total of 200 respondents were randomly interviewed were 80 (40 percent) were males, and 120 (60 percent) females. The majority of $97(48.5$ percent $)$ respondents were 26 years to 33 years, followed by 64(32.0 percent) respondents 34 years to 41 years. Most respondents were 87 (43.5 percent) unemployed, while only 81 (40.5 percent) were working. A total of 46 (23.0\%) were government workers, $37(18.5 \%)$ were private workers, 65 (32.5\%) owned their companies, and a large number 52 (26.0\%) were graduates. Please see Table-1 for information.

Table-1: Socio-demographic characteristics of respondents $(n=200)$

\begin{tabular}{clll}
\hline $\mathbf{S} /$ & Variables & Frequency & Percent $(\boldsymbol{\%})$ \\
$\mathbf{N}$ & & & \\
\hline 1. & Gender & 80 & $40.0 \%$ \\
& Male & 120 & $60.0 \%$ \\
2. & Female & & \\
& Age in years & 23 & $11.5 \%$ \\
& 18-25years & 23 & $48.5 \%$ \\
& 26-33years & 97 & $32.0 \%$ \\
& 34-4lyears & 64 & $8.0 \%$ \\
3. & E2years and above & 16 & $40.5 \%$ \\
& Employment status & & $43.5 \%$ \\
& Unemployed & 81 & $16.0 \%$ \\
4. & Self-employed & 87 & \\
& Occupation & 32 & $23.0 \%$ \\
& Government Employee & & $18.5 \%$ \\
& Private employee & 46 & $32.5 \%$ \\
& Owned business & 37 & $26.0 \%$ \\
\hline
\end{tabular}

[200(100 percent)], health consciousness. After the Covid-19

\section{A.Covid-19 Influences on Socialization}

The following were the identified effects of Covid-19 on socialization as 135(67.5 percent) admitted that Covid-19 affected the way they relate to others, affected their religious worship life [167(83.5 percent)], their buying pattern [110(55.0 percent)], affected people's exercise and physical activity [134(67.0 percent)], affected outing patterns outbreak, people avoided handshakes [140(70.0 percent)], avoided hugging [102(51.0 percent)], avoided hospitals for fear of being diagnosed with Covid-19 being approached by health care staff or patients [65(32.5 percent)]. The pandemic increased regular handwashing [70(35.0\%)], face mask $[180(90.0 \%)]$ and hand sanitizers $[83(41.5 \%)]$. It is listed in detail in
Table-2.

Table-2: Covid-19 influence on socialization

\begin{tabular}{llc}
\hline Variables & Frequency & Percent (\%) \\
\hline Covid-19 affected: & 135 & $67.5 \%$ \\
1. The way I relate with others & & $83.5 \%$ \\
2. My religious worship & 167 & $55.0 \%$ \\
3. My buying pattern & 110 & $67.0 \%$ \\
4. My exercise and physical activity & 134 & $100 \%$ \\
5. My outings & & $44.5 \%$ \\
6. My health consciousness & 200 & 89 \\
7. My personal hygiene & & \\
\end{tabular}


Since the outbreak of the Covid-19:

98

$49.0 \%$

1. I don't take or give handshakes

2. I don't give embrace

3. I avoid hospitals

4. I wash my hand often

5. I use my face mask whenever I go out

6. I use hand sanitizers

102

65

180

83

\section{$51.0 \%$}

$32.5 \%$

$35.0 \%$

$90.0 \%$

$41.5 \%$

\section{B.Hypothesis}

Covid-19 pandemic has no significant influence on socializing the people of Calabar Metropolis of Cross River State, Nigeria. As measured from questionnaire analyzes. The independent variable was pandemic control of Covid-19, while the dependent variable was citizens' socialization. The statistical research methodology adopted to check the hypothesis was basic regression. This result is set out in Table-3.

The result of the study showed that the Covid-19 pandemic correlation (R) coefficient and socialization of the Calabar Metropolis people is .194 , which meant that there was a substantial positive, strong correlation between Covid-19

Table-3: Simple regression analysis of the predictive influence of Covid-19 pandemic on socialization of the people of Calabar Metropolis of Cross River State, Nigeria $(n=200)$

\begin{tabular}{lcclll}
\hline Model & Sum of Square & df & Mean Square & F-ratio & p-level \\
\hline Regression & 230.873 & 1 & 230.873 & 21.836 & .000 \\
Residual & 5899.825 & 198 & 10.573 & & \\
Total & 6130.698 & 199 & & & \\
\hline
\end{tabular}

$\mathrm{n}=200 ; \mathrm{S} . \mathrm{E}=3.252 ; \mathrm{R}=.194 ; \mathrm{R}^{2}=.038$

\section{DISCUSSION OF FINDINGS}

The study showed that the Covid-19 outbreak affected people's social life in the Metropolis as people are now learning how to observe the social distance, avoid embrace, and a handshake, among others. This is similar to Jing, Lin, and Karen 's study finding (2020) that while social or physical distancing is antisocial, it has still proved to be the most important in controlling the pandemic. The study also showed that people had avoided crowded areas since the outbreak of Covid-19, influencing their outing routine, the pattern of activity, and other social activities such as religious worship, burials, weddings, holidays, and other social events. This is in tandem with Chen, $\mathrm{Xu}$, and Lei's (2020) assertion that adherence to social distancing, especially during burial ceremonies (funerals), weddings/marriage ceremonies, and other social events, can prevent 80 percent of the pandemic spread. This is consistent with Jaja, Anyanwu, and Jaja (2020) submitting that if universal precautions, such as proper spacing and avoiding crowded atmosphere, particularly in religious places, help to contain the pandemic. The writers (Jing, Lin \& Karen, 2020; Chen, Xu \& Lei, 2020; Jaja, Anyanwu \& Jaja, 2020) added that Covid-19 also had a pandemic and socialization of the Calabar Metropolis people. This suggested that pandemic Covid-19 affects the socialization of the Calabar Metropolis people. However, the adjusted R2 value of. 036 showed that only 3.6 percent of the Covid-19 pandemic outbreak would account for the variation in the socialization of the Calabar Metropolis population. Nonetheless, when the variance table analysis was tested, the result indicated $\mathrm{F}=21.836$, where $\mathrm{P}<.05(\mathrm{P}=.000)$ was rejected, and the null hypothesis was rejected because $\mathrm{P}$ was less than .05. This suggested that the Covid-19 pandemic has a significant influence on the socialization in Calabar Metropolis of Cross River State, Nigeria.

global impact on socialization. The hypothesis stated in this study showed that on socialization $(\mathrm{P}<.000)$ there is a significant influence of covid-19. This corroborates with Jeronimus' statement (2020) that the Covi-19 pandemic has influenced socialization globally. In further support, this observation, Alvis, Douglas, Shook, and Oosterhoff (2020) concluded in their analysis that the Covid-19 pandemic affected the socialization of the respondents.

\section{SUMMARY/CONCLUSION}

This study found a link between Covid-19 and socialization. Affected social areas included: interaction with others, handshakes, embrace, religious worships, exercise / physical activity, personal hygiene, and knowledge of health. The pandemic has also influenced people's company and hustle habits. The study concluded, however, that most respondents agreed that Covid-19 affects socialization, and a strong proportion agreed the social change that the pandemic brought as long as it helps them remain healthy and alive.

\section{RECOMMENDATIONS}

Based on the finding of this study, the following was recommended: 
i. Individuals should accept the social change the pandemic came with.

ii. Observing social distancing to contain the pandemic. iii. Increasing awareness on the reality of the pandemic to help people see the need to take precautionary measures.

iv. Use of face masks in public places and use of hand sanitizers where there is no water to wash hands.

\section{REFERENCES}

[1] Alvis, L., Douglas, R., Shook, N. J. \& Oosterhoff, B. (2020). Adolescents' prosocial experiences during the COVID-19 pandemic: Associations with mental health and community attachments. Prosocial Behavior and Adolescent Health, 1(1), 1-30.

[2] Chen, D., Xu, W. \& Lei, Z. (2020). Recurrence of positive SARS-CoV-2 RNA in COVID-19: A case report. International Journal of Infection Diseases, 93(1), 297-299.

[3] Jaja, I. F., Anyanwu, M. U. \& Jaja, C. I. (2020) Social distancing: how religion, culture, and burial ceremony undermine the effort to curb COVID-19 in South Africa. Emerging Microbes \& Infections, 9(1), 1077-1079.

[4] Jeronimus, B. F. (2020). Personality and the Coronavirus Covid-19 pandemic. University of Groningen Press, Netherlands.

[5] Jing, D. P., Lin J. W. \& Karen, M. L. (2020). Coronavirus disease 2019 (COVID-19) pandemic and pregnancy. American Journal of Obstetrics and Gynecology, 3(1), 1-11.

[6] Lai, C. C., Liu, Y. H. \& Wang, C. Y. (2020). Asymptomatic carrier state, acute respiratory disease, and pneumonia due to severe acute respiratory syndrome coronavirus 2 (SARS-CoV-2): Facts and myths. Journal of Microbiology, Immunology, and Infection, 2(1), 1-5.

[7] Lupia, T., Scabini, S. \& Pinna, S. M. (2020). 2019-novel coronavirus (2019-nCoV) outbreak: A new challenge. Journal of Global Antimicrobial Resistance, 21(1), 22-27.

[8] Sun, J., He, W. T. \& Wang, L. (2020). COVID-19: Epidemiology, evolution, and cross-disciplinary perspectives. Trends in Molecular Medicine, 10(1), 1-6.

[9] WHO (2020). Mental health and psychosocial considerations during the COVID-19 outbreak. Access on 12th May 2020, from http://www. WHO/2019-nCoV/MentalHealth/2020

[10] Wu, D., Wu, T. \& Liu, Q. (2020). The SARS-CoV-2 outbreak: What we know. International Journal of Infectious Diseases, 94(1), 44-48.

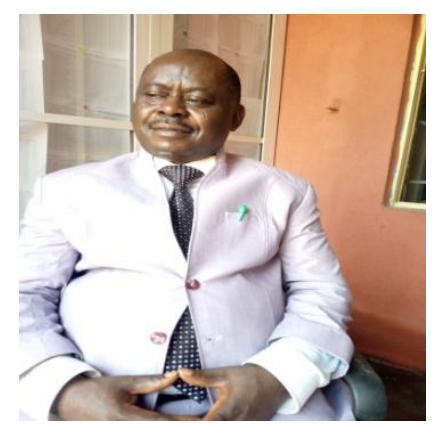

First Author: Edinyang, Sunday David, Is an Associate Professor in the Department of Social Science Education, Faculty of Education, University of Calabar, Calabar, Cross River State, Nigeria. He was a one time coordinator of Environment Education at the University of Calabar, also one time Post Graduate School Representative at the Department of Social Science Education, $\mathrm{He}$ is currently the head of Department of The Department of Social Science Education. He is form Nsit Atai Local Government of Akwa Ibom State, Nigeria. He got his Bachelor in Education Political Science degree from the University of Calabar, he also got his master degree and Ph.D. in Social Studies from the the same University. He is happily married and the marriage is blessed with six children (three boys and three girls). He is a prolific writer who has published several books and article as can be seen on his google scholar profile: https://scholar.google.com/citations?user=9gyvGaMAAAAJ\&hl=en.

Ogbaji, Dominic Ipuole is a Lecturer in the Department of Social Science Education, Faculty of Education, University of Calabar, Calabar, Cross River State. He has a Bachelor in Education Social Studies degree and currently pursuing his Masters and Ph.D. in Social Studies from the same department. He has co-authored several article.

Benedict, Helen Iwara, Is a Masters Degree Student with the Department of Social Science Education, Faculty of Education, University of Calabar, Cross River State, Nigeria. 